\title{
Fundamentación de la lectura significativa en transición, para fortalecer la lectura comprensiva y crítica
}

Artículo de reflexión.

Fecha de Recepción: 2 octubre 2017.

Fecha de Aprobación: 7 mayo 2018.

\section{Resumen}

La investigación que sustenta el presente documento atiende un interrogante: ¿cómo fomentar, mediante estrategias didácticas complementarias, la lectura significativa en los estudiantes del grado Transición de las sedes San Luis Cardonal y Barranco Negro de la institución? ${ }^{1}$ Conceptualmente, se retomaron elementos relacionados con competencias básicas para Transición, logografía, lectura significativa y trabajo colaborativo. Se implementó una propuesta de aula, en la cual el niño pudiera aproximarse a la lectura logográfica para que, cuando pase al nivel de básica primaria, haya

Sonia Elena Pineda Roncancio* Carlos Alberto Molina Rodríguez **

* Institución Educativa José María Córdoba, Boyacá (Colombia)

soniaepinedar@yahoo.es

** Leidy Amanda Valero Institución Educativa José María Córdoba, Boyacá (Colombia)

leidyamandavalero@gmail. com

*** Universidad Pedagógica y Tecnológica de Colombia, Boyacá (Colombia) camolina411@hotmail. com; carlos.molina@uptc. edu.co

1 Este trabajo parte del proyecto de investigación "Propuesta didáctica complementaria para transición: alternativa hacia la fundamentación de la lectura significativa”, desarrollado en la Institución Educativa José María Córdoba, Saboyá, Boyacá, sedes San Luis Cardonal y Barranco Negro.

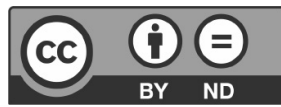
aprendizaje visual, taller, competencias comunicativas. 


\section{Introducción}

Una de las dificultades más evidentes observadas en nuestro sistema educativo, se relaciona con el proceso de alfabetización. Aunque el crecimiento de dicho sistema, desde mediados del siglo XX ha permitido incrementar las tasas de escolarización y de alfabetización de la mayor parte de la población colombiana (Martínez, 2003), los informes de diversos estudios acerca de la calidad de la educación tanto aquellos de carácter nacional como internacional, la opinión pública e incluso nuestra percepción como maestros, dejan ver una dificultad en la comprensión de los textos por parte de niños y jóvenes que, día a día, pasan por las instituciones escolares. Dicho de otra manera, aunque muchas personas consiguen descifrar el código escrito gracias a su paso por la enseñanza escolar, lo que supondría que la mayor parte de la población es capaz de leer correctamente, en concreto se observa que las habilidades para comprender muchos de los textos escritos son reducidas.

En la Institución Educativa José María Córdoba, ese panorama frente a la lectura quedó, en cierta medida, evidenciado con los resultados de las pruebas Saber aplicadas a los estudiantes (especialmente, en grados tercero y quinto), pues estos no solo mostraban un puntaje bajo frente al promedio nacional: los resultados también apuntaban a un bajo nivel de desempeño en la competencia comunicativa lectora y el componente semántico.
La razón de esas dificultades puede estar en que los niños no consiguen entender lo que leen tanto en referencia al significado de las palabras que forman un texto, como en relación con la comprensión global del mismo. Esta situación preocupa a toda la institución, dado que estaría relacionada con las dificultades de los estudiantes de educación media (grados $10^{\circ}$ y $11^{\circ}$ ) para aplicar una lectura crítica, pues no habrían desarrollado las habilidades de comprensión lectora propias de la educación básica. Entonces, se hace prioritario el trabajo en la educación inicial mediante el replanteamiento de estrategias de enseñanza de la lectura en el grado transición, ello con el fin de establecer bases suficientes para que niños y niñas fortalezcan su proceso de aprendizaje a partir de una lectura significativa.

Esa preocupación por la lectura no es totalmente nueva. Desde la misma conformación de los sistemas escolares a finales del siglo XVIII e inicios del siglo XIX, la lectura constituyó una preocupación fundamental, junto con la escritura (cuya enseñanza se separaba de la primera) y la aritmética. Así lo señala Ríos (2015): Desde la emergencia de la escuela en Colombia en la época colonial, hasta nuestros días, la aritmética, la lectura y la escritura, por excelencia, han sido los saberes que han permanecido en el centro de cualquier reforma curricular o plan de estudios (p. 13).

Por supuesto, los objetivos que se trazan hoy para la enseñanza y el aprendizaje de la lectura son diferentes de aquellos 
propuestos hace dos siglos relacionados con la idea de una cohesión a través de la lengua nacional. Como efecto de las diferentes evaluaciones que se realizan a la calidad de la educación colombiana, se exige que los estudiantes desarrollen competencias comunicativas; en particular, que aprendan a comprender un texto, no solo a decodificar lo que este dice.

En el marco de esa preocupación, el proyecto que subyace al presente artículo procuró atender a esa necesidad de potenciar los procesos de lectura con los estudiantes de Transición, con un trabajo que inicia en 2017 y se espera continuar hasta 2020, pretendiendo así optimizar los niveles de lectura inicial y establecer las bases de formación en cuanto al carácter significativo del aprendizaje, no apenas como una mera transmisión de contenidos. En esa dirección, vale recordar con Partido (2013) que: la lectura es un proceso de obtención de significados de un texto escrito, es una interacción entre el lector y el texto que tiene una forma gráfica que se procesa como lenguaje; en este sentido, la lectura tiene como finalidad la construcción de significados (p. 1).

Desde esta perspectiva, y con base en una revisión de varios asuntos que enmarcan los procesos que se dan en el grado Transición, se ha diseñado una propuesta didáctica mediante la aplicación de talleres que, teniendo como referencia la etapa logográfica de la lectura la cual consiste en el reconocimiento de palabras familiares por su forma y disposición, se fundamentan en una lectura significativa que parte desde el contexto, en tanto establece relaciones, encuentra elementos de comprensión $\mathrm{y}$ vínculos con el mundo que rodea al estudiante y permite la interacción de manera creativa y lúdica.

Con este panorama, el artículo se encuentra estructurado en tres partes: en la primera se tratan los principales referentes conceptuales acerca de la enseñanza y el aprendizaje de la lectura, que permitieron fundamentar la propuesta diseñada; en la segunda parte, se describen los principales rasgos del diseño metodológico elaborado; en la tercer y última parte, se presentan algunos resultados y discusiones que quedarían abiertas a partir de la implementación de la propuesta.

\section{Referentes conceptua- les y metodológicos de la propuesta}

Para poder alcanzar el objetivo principal de este proyecto, fue necesario buscar información acerca de otras propuestas relacionadas con el tema de investigación. Así, a nivel mundial, se encontraron dos propuestas de aula que hacen referencia a la enseñanza aprendizaje de la lecto-escritura y la lectura en el nivel inicial; estas propuestas ofrecen estrategias para adquisición de la lecto-escritura para desarrollar el potencial del niño en los procesos básicos de asimilación del código de la lengua, tanto oral como escrito en el grado primero (Correa, 2000; Lara, 2008).

En el ámbito nacional, se hallaron resultados de tres proyectos: uno
Para poder alcanzar el objetivo principal de este proyecto, fue necesario buscar información acerca de otras propuestas relacionadas con el tema de investigación. 
2 [Las competencias] Comunicativas: corresponde al conjunto de conocimientos y habilidades empleadas por el niño para la construcción de significados y la atribución de sentido a su experiencia vital, los cuales pueden expresarse de forma oral y escrita. Tales significados y sentidos permiten a los niños alcanzar una comprensión del mundo que les rodea y de sí mismos, además de ofrecerles la posibilidad de entender sus propios sentimientos, deseos, pensamientos e intenciones, así como los que aquellos que les rodean y con quienes establecen interacción.

Entre los funcionamientos cognitivos, se resaltan la anticipación, la elaboración del discurso en la expresión de ideas y la textualización y construcción de reglas del sistema de notación (MEN, 2010, p. 28). relacionado con el cuento como estrategia pedagógica para generar aprendizajes significativos en el grado primero; el segundo, leer $\mathrm{y}$ escribir en la escuela; y, por último, experiencias de lecto-escritura con los niños en el grado primero. Las tres enmarcadas en generar aprendizajes significativos en los procesos de lectura en el grado primero, abriendo espacios para que los estudiantes adquieran elementos y medios de expresión, mediante actividades y experiencias de lectoescritura (Castañeda, 2008; Giraldo, 2010; Lozano, 2013).

A partir de una revisión de diferentes materiales relacionados con el tema y la cuestión planteada en el proyecto, se identificaron cinco aspectos que delimitan la propuesta diseñada. Dadas las limitaciones de este escrito, los aspectos abordados constituyen apenas un esquema general; sin embargo, con los elementos aquí ofrecidos se espera dar cuenta de ese marco referencial.

El primer aspecto corresponde a las competencias para el grado transición. Para empezar, debe recordarse que el Ministerio de Educación Nacional (MEN) define genéricamente las competencias como el conjunto de conocimientos, habilidades, actitudes, comprensiones y disposiciones cognitivas, socio afectivas $y$ psicomotoras apropiadamente relacionadas entre sí para facilitar el desempeño flexible, eficaz y con sentido de una actividad en contextos relativamente nuevos y retadores (MEN, 2010, p. 20). Para el caso de transición, se establecen cuatro tipos de competencias básicas: comunicativas, ciudadanas, matemáticas y científicas (MEN, 2010, pp. 28-30)2. Cada grupo está asociado con unos funcionamientos cognitivos que deben ser registrados en relación con esas competencias.

El segundo referente para la propuesta, se relaciona con fundamentos conceptuales $y$ didácticos del lenguaje en el grado transición. Aquí, es importante recordar que tanto la escuela como la familia constituyen espacios fundamentales en la configuración individual del niño, siendo la segunda un poco más determinante que la primera. Con todo, el espacio escolar, en tanto constituye un ambiente educativo, cumple un papel muy importante en la formación del estudiante; en ese sentido, el docente se hace responsable de la creación de escenarios que permitan a sus estudiantes aprender a aprender, mediante el recurso a la resolución de problemas y la construcción de conocimiento a partir de referencias a su entorno. Es claro también que un buen ambiente de aprendizaje favorece el trabajo autónomo y colaborativo en los niños, donde es necesario una relación cercana entre docente $\mathrm{y}$ estudiante que, sin desdibujar sus respectivos roles, se base en el diálogo, el respeto por el ritmo de aprendizaje y las condiciones específicas de la población que se atiende, así como el desarrollo integral (cognitivo, afectivo y social) de sus estudiantes.

Un principio para la enseñanza en las instituciones educativas, acorde con lo señalado anteriormente, es que el niño cumple un papel importante 
como agente de su propio proceso de formación(Nova, 2015) o como algunos señalan, construye conocimiento; el "niño compara, excluye, ordena, hace categorías, reformula, comprueba, formula hipótesis y reorganiza”, entre otras posibilidades del lenguaje (Ferreiro y Teberosky, 1979; citado en MEN, 2010b, p. 51). Junto con ello, se ha de reconocer, según lo propuesto por el mismo MEN, que el aprendizaje de una lengua es producto de una interacción con el mundo, donde el sujeto busca la manera de explicar los fenómenos del mundo o trata de reacomodar sus esquemas de pensamiento. Eso es, precisamente, a lo que puede llamarse aprendizaje.

El niño, en la interacción con su entorno sociocultural, adquiere algunos conocimientos (también llamados ideas previas), los cuales, al llegar a la escuela, se asimilan y replantean con los saberes llamados científicos, para dar lugar a la construcción de un aprendizaje significativo (MEN, 2010, pp. 51-52). En ese contexto, el MEN ha implementado un enfoque comunicativo de aprendizajes significativos para el área del lenguaje.

La significación es un proceso por el cual el ser humano va interpretando su realidad, para transformar sus esquemas de pensamiento mediante una visión del mundo que comprende las dimensiones cognitiva (Pinedo \& Yañez, 2017), afectiva, comunicativa y estética. Las interacciones producen la significación como un proceso que se cumple al menos en tres niveles: la representación de las cosas de que hablamos, la manera como concebimos las cosas de que hablamos (configuración lógica) y las razones por las cuales hablamos de las cosas de que hablamos de la manera como las concebimos.

El lenguaje permite convertir la experiencia humana en significación; a través de él, el niño construye su identidad, se relaciona con el mundo conceptualiza, se inserta en su comunidad.

En diferentes oportunidades, se ha señalado la reducida significación de las prácticas escolares, que habrían reducido la lectura a un acto mecánico de supuesta reproducción oral de grafías y a la comprensión al acto de recuperar algunas veces, de memoria la información de un texto. Desde hace buen tiempo, diferentes investigaciones han señalado que para leer no es suficiente con reconocer las letras (sea por su grafía o su fonética), dado que la lectura es un complejo proceso de producción de sentido. Lectores expertos y principiantes, se diferencian en la utilización y el dominio de diferentes estrategias en el acto de leer. Aquí, se ha de entender por estrategia el esquema usado para obtener, evaluar y utilizar información conseguida en experiencias previas, con el fin de comprender el texto (MEN, 2010, p. 62).

La lectura en la educación inicial cumple objetivos en las áreas social, intelectual, afectiva $y$ motora, íntimamente relacionadas con la preparación del niño y la niña para su escolaridad regular. No se trata de un primer grado
El lenguaje permite convertir la experiencia humana en significación; a través de él, el niño construye su identidad, se relaciona con el mundo conceptualiza, se inserta en su comunidad. 
para los más pequeños, pues entre sus objetivos no está la enseñanza formal de la lectura y la escritura. Sin embargo, el docente tiene la responsabilidad de disponer las condiciones para propiciar la introducción de niños y niñas al mundo de la cultura escrita mediante el acceso al periódico, a letreros, cuentos y libros (Flores \& Martín, 2006, p. 1).

El tercer referente corresponde a los Derechos Básicos de Aprendizaje $(D B A)$, en este caso aquellos dirigidos específicamente al grado Transición. Estos DBA son entendidos como:

\begin{abstract}
[] el conjunto de aprendizajes estructurantes que construyen las niñas y los niños a través de las interacciones que establecen con el mundo, con los otros y consigo mismos, por medio de experiencias y ambientes pedagógicos en los que está presente el juego, las expresiones artísticas, la exploración del medio y la literatura (MEN, 2016, p. 5).
\end{abstract}

Pese a que sobre los DBA pueda haber algunos cuestionamientos relativos a su función como una suerte de estándar, éstos están pensados para servir de orientación al docente de Transición en la configuración de ambientes de aprendizaje y de mediaciones pedagógicas con niños y niñas. En relación con la lectura y el lenguaje, se destacan dos asuntos: por un lado, se marca la importancia de que se exprese y represente aquello que se observa, siente, piensa e imagina por medio de diferentes mecanismos como juegos, música, dibujos, expresión corporal (DBA 7); por el otro lado, se destaca que el niño identifique las relaciones sonoras en el lenguaje oral y que, además, establezca relaciones con diferentes clases de textos, formatos e intenciones comunicativas (DBA 8, 9 y 10).

El cuarto referente considerado en este trabajo, se relaciona con los procesos cognitivos en el aprendizaje de la lectura inicial, los cuales inician desde la misma gestación y en lo que influyen factores de diverso orden: biológico, genético, ambiental. Tales factores son determinantes para el aprendizaje de la lectura, la cual se produce con mayor o menor facilidad según las condiciones del medio en que el niño se desenvuelve. El proceso lector se inicia, entonces, antes de cursar el primer año escolar. Para que este alcance una adecuada comprensión lectora, no solo depende del currículo o de los profesores, sino de las condiciones ambientales y culturales del medio, así como de las habilidades propias para efectuar acomodaciones mentales frente a los componentes del lenguaje escrito (Bravo, 2000, p. 52).

En el aprendizaje de la lectura, es posible distinguir tres etapas: logográfica, alfabética y ortográfica. Cada una de estas etapas, tiene sus propios rasgos que conducen desde el reconocimiento inicial de significados asociados a ciertos símbolos y signos visuales, hasta la retención y el reconocimiento de palabras completas. Sobre la primera de estas etapas, que corresponde al tipo de trabajo que se realiza en el grado Transición, Frith (citado en Bravo, 2000 , p. 54) indica que en esta fase ocurre el fomento del interés del lector 
en el universo escrito y reconoce, de manera global, algunas configuraciones gráficas, además de establecer relaciones entre lenguaje escrito y lenguaje oral. En esta etapa, el lector tiene ciertas ideas acerca de lo que se puede leer y lo que no, y aprenderá a reconocer algunas palabras como su nombre, logotipos de productos utilizados, títulos de cuentos muy familiares, etc. Aunque el niño no es capaz de descifrar para acceder al significado de las palabras, sí recurre a la búsqueda de información y establece hipótesis a través de los formatos, los dibujos, el contexto o el adulto al que le pueden preguntar (Gamundí, 2014, p. 12).

Para el aprendizaje lector inicial, sería preciso aplicar diferentes estrategias que introduzcan en el lenguaje escrito. A partir de la revisión realizada, se encuentran las siguientes formas de realizar esa introducción.

a) Estrategia lectora fonológica. Se debe tomar conciencia que para decodificar las palabras escritas hay que transformar las letras en sonidos asociados con el propio lenguaje oral. Esta se aplica para discriminar, segmentar, modificar e integrar las secuencias fonográficas de las palabras que culminan con su integración y su articulación, lo cual permite reconocerlas auditivamente (Bravo, 2000, pp. 57-58).

b) Estrategia visual ortográfica. Requiere que los niños reconozcan los signos gráficos pronunciables dentro de un contexto ortográfico. La retención visual ortográfica de las palabras en la memoria no se hace independientemente de la discriminación de sus fonemas y sílabas, sino que, de acuerdo con (Ehri, 1998; citado por Bravo, 2000, pp. 59-60), es un reconocimiento visual que se efectúa por vía fonológica. El éxito de este procesamiento depende de que los niños recuerden su pronunciación $\mathrm{y}$, en los posible, su significado, lo mismo que la atención visual a las diferencias ortográficas entre las palabras.

c) Estrategia semántica. Implica asociar la secuencia fonográfica con su significado, pues sin este no hay lectura, solamente decodificación, como sucede con los niños hiperléxicos. Para efectuar este proceso, no basta con que se tenga conocimiento del vocabulario del texto, es necesario establecer el acceso de las palabras y frases con la red semántica personal. Algunas investigaciones muestran que recurrir al contexto favorece el reconocimiento de las palabras en los niños que son buenos lectores, pero que no sucede lo mismo con los que tienen dificultades para leer. Es decir, mientras los niños no dominen el procesamiento fonológico y el visual ortográfico de las palabras, no podrían suplir exitosamente estas deficiencias, recurriendo al contexto para reconocerlas (Bravo, 2000, p. 62).

El quinto y último referente tomado en cuenta, se relaciona con la lectura significativa. Esta se puede definir como un proceso que no se queda en la mera 
lectura, sino que trasciende; es decir, tiene en cuenta el contexto donde se desenvuelve el estudiante. En fin, es una lectura que tiene sentido para los estudiantes y no una simple obligación. La base de esta idea es el aprendizaje significativo, el cual se plantea a partir de las teorías de Benjamin Bloom, Robert Gagne, David Ausubel, Carl Rogers y Lev Vygotsky, quienes, desde distintos ángulos teóricos, buscan darles a los estudiantes un lugar como creadores en la práctica de la lectura.

La lectura y la escritura han sido reconocidas como una interrelación comunicativa donde dos habilidades del lenguaje (leer y escribir) no pueden estar la una sin la otra (de ahí que, en algunos casos se hable de lectoescritura). Como bien se sabe, son procesos continuos y estrechamente vinculados, donde si se da un paso con la lectura, entonces se debe avanzar con la escritura; esto posibilita desarrollar en los niños estas habilidades y alcanzar consigo un aprendizaje significativo (Montealegre, 1995).

Parafraseando a Emilia Ferreiro, el ser humano debe ser lector y crítico de todo aquello que lee, de manera que encuentre el significado de la palabra escrita; es decir, la lectura es un acto donde el ser humano acepta la asignación de encontrarle sentido y coherencia a lo que el autor refleja en su escrito. Por tanto, el lector debe reaccionar al momento de leer, buscando sentido de lo que se quiere expresar. Siempre tomamos la lectura como una actividad que nos permite identificar, decodificar y analizar lo que otra persona quiere decir, debemos tener en cuenta que no se trata de decodificar signos, sino que se nos invita a tomar responsabilidad de buscar el sentido del texto, para que mediante la argumentación podamos transformar los conocimientos previos por aquellos aprendidos (Guzmán, Gutiérrez, \& Chalela, 2009).

Antes de llegar a las aulas de clase, los niños inician su aprendizaje de lectura y escritura de acuerdo con los contextos en que se desenvuelven. Es usual encontrar que, a quienes viven en entornos urbanos, se les facilita entrar en contacto con factores que inciden significativamente en la lectura: T.V., avisos publicitarios, uso de medios tecnológicos, ambientes familiares que les permiten distinguir los dibujos de las letras y los números, etc. En cuanto a los niños que viven en el campo, estos regularmente no encuentran el mismo acceso a esos medios que facilitarían el proceso de lectura a temprana edad. El docente desempeña aquí un papel importante en el aprendizaje de la lectura en los niños, en tanto debe echar mano de los recursos que tiene a su alcance para continuar la formación de su proceso lector. Por supuesto, no es algo que se haga exclusivamente en el primer grado; por eso, el llamado grado transición se convierte en un campo de práctica y de exploración para la lectura y la escritura.

Ahora bien, junto a estos referentes de orden más conceptual, también son necesarios algunos otros que se encuentran más del lado de lo metodológico, desde los cuales se 
definen algunas de las formas de operar que aparecen en la propuesta diseñada que además estaría en permanente proceso de retroalimentación y ajuste. Entre estos, se destaca el aprendizaje colaborativo. Al respecto, es importante considerar la referencia que Herrera (2003) hace a Vigotsky, cuando señala que: El aprendizaje despierta una variedad de procesos de desarrollo que son capaces de operar sólo cuando el niño interactúa con otras personas y en colaboración con sus compañeros (p. 3)

Esta definición es importante, por ejemplo, en un sistema como el de aulas multigrado conocido como escuela nueva ${ }^{3}$, donde el docente se ve enfrentado a trabajar a la vez con diferentes grados, y por esto se ve la necesidad de recurrir al aprendizaje colaborativo, guiando a los estudiantes para integrarse en grupos y desarrollar sus habilidades mediante la cooperación entre ellos, contribuyendo a la formación personal y académica. Es aquí donde el rol del docente pasa de ser un informante y centro del saber y el conocimiento a ser un facilitador del aprendizaje, a motivar la participación, crear las condiciones y el clima para brindar ambientes apropiados de aprendizaje. El trabajo colaborativo desempeña un papel importante en la formación de los estudiantes, donde junto con sus compañeros de los otros niveles comparten saberes y experiencias que contribuye, de manera enriquecedora y significativa, al conocimiento.

Otro asunto que es importante señalar es el de las estrategias didácticas, las cuales pueden entenderse como acciones planificadas por el docente, con el objetivo de que el estudiante logre la construcción del aprendizaje y se alcancen los objetivos planteados. Una estrategia didáctica es, en un sentido estricto, un procedimiento organizado, formalizado y orientado a la obtención de una meta claramente establecida. Su aplicación en la práctica diaria requiere del perfeccionamiento de procedimientos y de técnicas, cuya elección detallada y diseño son responsabilidad del docente (UNED, 2003, p._1).

\section{La metodología del proyecto.}

El enfoque del proyecto es cualitativo: presenta descripciones interpretativas y trata de identificar la naturaleza profunda de las realidades, su estructura dinámica da razón de los comportamientos y manifestaciones de los estudiantes en su entorno social para poder concluir el porqué de las cosas. Con este trabajo se pretende, en el fondo, partir de un diagnóstico de un problema para determinar las habilidades, oportunidades, fortalezas y actitudes de los estudiantes frente a eventos y circunstancias que se presentan en el contexto escolar.

En ese contexto, se pueden diseñar diversas actividades que se desarrollan dentro de la institución, que más tarde son sometidas a la observación, reflexión y cambio. Esto se corresponde con los principios de la perspectiva de la investigación acción, porque se trata de una actividad colectiva
3 Es importante diferenciar ese sistema de aulas multigrado del movimiento homónimo de inicios del siglo XX que procuraba transformar las prácticas educativas en el sistema escolar y que se apoyó en desarrollos de disciplinas como la medicina, la psicología y la sociología, entre otras. 
caracterizada por la participación reflexiva, en búsqueda de un cambio y del compromiso de generar un plan de acción, encaminado positivamente a la integridad de los estudiantes y docentes.

Este proceso se relaciona también con la exploración y la reflexión como momentos que permiten comprender el problema que se plantea; la planificación se relaciona con las acciones organizadas que se siguen para alcanzar el cambio que se propone, junto con los métodos y las estrategias a seguir; la acción hace referencia a la práctica ejecutada con el grupo; y finalmente, la evaluación, la cual permite mostrar el sentido del proceso, así como los problemas de la acción estratégica, la validación de los objetivos y la hipótesis planteada, que en este caso giran en torno a las situaciones cotidianas y a la forma como se trabaja el desarrollo de la lectura significativa en el nivel inicial.

Elliot define la investigación-acción como un estudio de una situación social con el fin de mejorar la calidad de la acción dentro de la misma (citado en Murillo, 2010, p. 3). La investigación-acción educativa se utiliza para describir una serie de actividades que realiza el docente dentro del aula de clase, con fines tales como: el desarrollo curricular, profesional, los planteamientos de programas educativos, los sistemas de planificación o la política de desarrollo. Estas tienen en común la identificación de estrategias implementadas y luego sometidas a observación, reflexión y cambio. Es un instrumento que genera cambio social y conocimiento en el campo educativo sobre la realidad social, dando autonomía y poder a quien la realiza. Lewis argumenta que se podía lograr en forma simultánea avances teóricos y cambios sociales (citado en Murillo, 2010, p. 3).

En correspondencia con esta perspectiva, para el desarrollo del proyecto, se diseñó una propuesta didáctica estructurada mediante talleres, a partir de la lografía que fomente la lectura significativa y global en los estudiantes del grado transición de las sedes San Luis Cardonal y Barranco Negro, de la Institución Educativa José María Córdoba de Merchán del municipio de Saboyá. También, se han tenido en cuenta como instrumentos de recolección de información: a) la observación directa en los estudiantes; b) la elaboración de un diario de campo que registre hechos susceptibles de ser interpretados; c) un grupo focal cuyo propósito es hacer que surjan actitudes, sentimientos, creencias, experiencias y reacciones en los participantes (Díaz, Gamez, Rodríguez, \& Vega, 2014, p. 2); d) un análisis apoyado en los anteriores instrumentos y en el índice sintético de calidad para determinar las falencias de los estudiantes, y así poder diseñar estrategias pedagógicas que tiendan superar y solucionar las dificultades que presentan en el desarrollo de la lectura significativa.

Con base en estos diferentes elementos conceptuales y metodológicos, los cuales se han puesto en juego en correspondencia con las preguntas $y$ 
los propósitos planteados, se diseñó la propuesta Las abejitas lectoras. Como se ha mencionado antes, la competencia lectora es primordial para el desarrollo de otras competencias básicas. Además, la lectura es significativa cuando el estudiante incorpora su vocabulario y lo contextualiza de forma global; es decir, da sentido a las palabras que utiliza en su cotidianidad. Así, en el desarrollo de este proyecto, a partir de la investigación acción, se pretende intervenir a los estudiantes de transición mediante la aplicación de una propuesta didáctica, la cual consiste en desarrollar una serie de talleres basados en la etapa logográfica de la lectura, en la cual el niño hace un reconocimiento visual de las palabras como un todo, pero sin interpretar el código convencional.

Con esta propuesta, se busca que los niños asimilen palabras de su entorno, las interioricen por medio de diferentes actividades didácticas planeadas, se apropien de su significado y puedan llegar a una lectura contextualizada que les permitan adquirir con mayor facilidad la competencia lectora. De ahí que, al pasar al nivel de básica y media, los estudiantes de transición ya hayan adquirido inicios de una lectura global y estén más familiarizados con vocabulario que faciliten la apropiación de nuevos conceptos a los que se verán enfrentados con las actuales exigencias educativas. Se considera pertinente actuar desde la base con la finalidad de que a mediano y largo plazo se mejore la lectura comprensiva, interpretativa y crítica en el nivel básico y medio de la institución.
$\mathrm{Si}$ se reconoce que la lectura es el camino hacia el conocimiento, pues pone a prueba saberes previos de cada uno de los lectores, llama a la comprensión, la reflexión y la crítica, y rompe con todos los esquemas que obstaculizan el conocimiento; por ello, se debe propender por formar hábitos de lectura y escritura con sentido y significado. Esta es una estrategia pedagógica que se convierte en una herramienta didáctica para generar aprendizajes significativos, donde los estudiantes sientan goce y placer en el desarrollo de las actividades propuestas dentro y fuera del aula de clase.

También, con la experiencia como docentes de preescolar, durante varios años y los resultados de las pruebas saber, que no son satisfactorios para la institución, se ha hecho una reflexión acerca de los procesos de aprendizaje que se vienen implementando. De ahí que, se considere importante plantear una propuesta didáctica complementaria para fomentar la lectura significativa y global en el grado transición. A continuación, se indican los aspectos centrales de la propuesta.

Grupo focal. Como punto de partida, se conformó el grupo focal integrado por los compañeros docentes de nivel de básica primaria de la Institución Educativa José María Córdoba, quienes participaron en el proceso de una entrevista estructurada en tres momentos: individual, grupal y general. La primera, consistió en aplicar una entrevista a cada uno de los compañeros a partir de la cual aportaron sus ideas desde su experiencia en el aula con los
Grupo focal. Como punto de partida, se conformó el grupo focal integrado por los compañeros docentes de nivel de básica primaria de la Institución Educativa José María Córdoba, quienes participaron en el proceso de una entrevista estructurada en tres momentos: individual, grupal y general 
estudiantes; la segunda, se organizó con grupos para que ellos compartieran las respuestas obtenidas en cada pregunta y establecer acuerdos; y en la tercera, se hizo una confrontación entre los dos grupos.

Como resultado de esta entrevista, se concluyó que algunos de los docentes encuentran pertinente la enseñanza de la lectura en transición; manifiestan que se debe implementar la lectura de imágenes, símbolos y gráficos y formar las bases para ingreso a la básica primaria; mientras que otros están en desacuerdo: opinan que se debe trabajar, exclusivamente, actividades de aprestamiento, motricidad y desarrollo de dimensiones. Al indagar acerca de la forma como se aborda el proceso de lectura en transición, la gran mayoría estuvo de acuerdo en el uso de estrategias a través de imágenes, cuentos y textos. En cuanto al apoyo en referentes teóricos, solo dieron a conocer el nombre de algunos autores, hecho que evidencia que muy pocos tienen conocimiento en este aspecto, porque no han trabajado en este nivel y otros aplican la enseñanza llamada tradicionalista. Además, dieron a conocer diversas dificultades en cuanto a la enseñanza de la lectura que se relacionan con la motricidad fina, lateralidad, direccionalidad, expresión, comunicación y el trabajo multigrado.

Conducta de entrada. Se consideró pertinente en esta fase diagnóstica, aplicar una prueba de entrada a los estudiantes de transición. Con ella, se pretendía indagar acerca del nivel de competencia lectora con que llegan los estudiantes a la educación formal. Esta actividad consistió en presentar a los niños una hoja con imágenes relacionadas con su medio social y, a la vez, un grupo de palabras correspondientes a los nombres de dichas imágenes para que los niños las correlacionaran, según su conocer. Lo anterior con el fin de formalizar un análisis diagnóstico de los saberes previos con los que cuentan los niños al llegar a la educación formal.

Se pudo observar que los niños realizaron interpretación de la imagen y la relacionaron con el medio que lo rodea, pero no reconocen el grafema o fonema que identifica el nombre de las imágenes.

Diseño de la propuesta - Las abejitas lectoras y su relación con los $D B A$. Con el interés de cumplir con el objetivo principal de la propuesta, se diseñaron diez (10) talleres con la siguiente esquema básico: tema, objetivo, actividades, cierre y recursos donde se presenta actividades de motivación y enlace con los saberes previos; desarrollo, se trabaja con estrategias prácticas que sirve de apoyo para que el niño asimile mejor el aprendizaje; y, finalmente, el cierre que permite la verificación y el desarrollo de competencias en los niños para relacionarlas con su diario vivir. Dichos talleres se pueden encontrar en la siguiente dirección del blog creado como un aporte educativo de lectura significativa en el nivel inicial, cuya dirección electrónica es: http:// significacioninicial.blogspot.com.co.

De igual forma, se reconoció que los DBA estipulados por el Ministerio 
de Educación Nacional para el grado transición, tienen dentro de algunos de sus propósitos que las niñas y los niños conciban la lectura de manera global y significativa. De ahí que, la propuesta didáctica de la cual se está informando en el presente artículo se constituye en una alternativa complementaria, que permitirá desarrollar potencialmente el proceso de lectura en el nivel inicial.

Tabla 1. Matriz de diseño de talleres "Abejitas lectoras".

\begin{tabular}{|c|c|c|c|c|}
\hline SEMANA & EJE TEMÁTICO & TALLER & OBJETIVO & $\begin{array}{c}\text { PALABRA } \\
\text { SIGNIFICATIVA }\end{array}$ \\
\hline 1 & \multirow{3}{*}{ ME CONOZCO } & $\begin{array}{l}\text { TENGO UN } \\
\text { NOMBRE }\end{array}$ & $\begin{array}{l}\text { Reconocer su propio nombre } \\
\text { y diferenciarlo con el de sus } \\
\text { compañeros. }\end{array}$ & $\begin{array}{l}\text { Nombre de cada estudiante } \\
\text { y el de sus compañeros. } \\
\text { Ejemplo: MAUREN, } \\
\text { Mauren. }\end{array}$ \\
\hline 2 & & EL ESPEJO & $\begin{array}{l}\text { Identificar y señalar las partes del } \\
\text { cuerpo relacionándolas con las } \\
\text { palabras que las nombran. }\end{array}$ & Cabeza, manos, boca. \\
\hline 3 & & $\begin{array}{l}\text { ACTORES } \\
\text { TALENTOSOS }\end{array}$ & $\begin{array}{l}\text { Identificar en cada uno de los } \\
\text { niños sus gustos, actitudes y } \\
\text { aptitudes para que se expresen libre } \\
\text { y espontáneamente. }\end{array}$ & Bailar, colorear, recitar. \\
\hline 4 & \multirow{3}{*}{$\begin{array}{l}\text { CÓMO ES MI } \\
\text { FAMILIA }\end{array}$} & $\begin{array}{l}\text { MI GRUPO } \\
\text { FAMILIAR }\end{array}$ & $\begin{array}{l}\text { Reconocer su grupo familiar y la } \\
\text { importancia de formar parte de él. }\end{array}$ & $\begin{array}{l}\text { Papá, mamá, hermano, } \\
\text { hermana. }\end{array}$ \\
\hline 5 & & $\begin{array}{l}\text { EL VESTIDO ME } \\
\text { ABRIGA }\end{array}$ & $\begin{array}{l}\text { Relacionar imágenes de las prendas } \\
\text { de vestir con las palabras que las } \\
\text { nombran. }\end{array}$ & Pantalón, falda, zapatos. \\
\hline 6 & & BUENOS MODALES & $\begin{array}{l}\text { Interiorizar en los niños, buenos } \\
\text { modales o pautas de conductas } \\
\text { adecuadas en el hogar y en la } \\
\text { escuela. }\end{array}$ & Por favor y gracias \\
\hline 7 & \multirow{3}{*}{$\begin{array}{l}\text { CÓMO ES MI } \\
\text { CASA }\end{array}$} & CASITA PARA VIVIR & $\begin{array}{l}\text { Identificar las diferentes partes de la } \\
\text { casa y relacionarlas con la palabra } \\
\text { que los nombra. }\end{array}$ & Casa, baño. \\
\hline 8 & & $\begin{array}{l}\text { PRACTIQUEMOS } \\
\text { HÁBITOS DE ASEO }\end{array}$ & $\begin{array}{l}\text { Fomentar hábitos de aseo en } \\
\text { los niños y familiarizarse con } \\
\text { los nombres de algunos de sus } \\
\text { elementos. }\end{array}$ & Cepillo, jabón. \\
\hline 9 & & $\begin{array}{l}\text { APRENDO } \\
\text { JUGANDO }\end{array}$ & $\begin{array}{l}\text { Permitir que los niños compartan } \\
\text { a través del juego, una sana } \\
\text { convivencia y a la vez reconozcan el } \\
\text { nombre de sus juguetes preferidos. }\end{array}$ & Carro, muñeca, pelota, \\
\hline 10 & $\begin{array}{l}\text { LAS COSAS QUE } \\
\text { ME RODEAN }\end{array}$ & $\begin{array}{l}\text { CUIDO MIS ÚTILES } \\
\text { ESCOLARES }\end{array}$ & $\begin{array}{l}\text { Identificar el nombre de los útiles } \\
\text { escolares más comunes. }\end{array}$ & Cuaderno, lápiz, colores \\
\hline
\end{tabular}

Fuente: elaboración propia. 
Como fase final de valoración de aprendizaje significativo, se inició con un proceso de repaso, en el cual se implementó una aplicación educativa diseñada con el programa de Jclick, con actividades interactivas relacionadas con los talleres desarrollados
El planteamiento de los talleres se hizo a partir de cuatro ejes temáticos: el primero se denomina "me conozco" para las semanas 1,2 y 3 , dividido en tres talleres; el taller número uno es el nombre de los niños, por la importancia que tiene cada uno de ellos para identificarse, además lo diferencia y se familiariza con sus compañeros, también identifica el sonido de las letras fortaleciendo la conciencia fonológica. El número dos, denominado "El espejo", enfatizó en las partes del cuerpo con el fin de identificar, señalar y mencionar las principales partes teniendo en cuenta la cantidad. En el tres, "Actores y talentos", se desarrollaron las habilidades y talentos con el fin de expresar sus gustos, actitudes y aptitudes mediante el canto, recitar, colorear y bailar.

El segundo eje temático se refiere a -Cómo es mi familia- para las semanas 4, 5 y 6. Allí, se trabajaron tres actividades: se inició con el "Grupo familiar", cuya finalidad consistió en conocer los integrantes de la familia y la importancia de formar parte de ella; luego, se trabajó la actividad "El vestido que me abriga" permitiéndole relacionar las prendas de vestir con las palabras que las nombran; se finalizó con los "buenos modales" para que los niños interioricen y pongan en práctica como pautas de conducta adecuadas en el hogar y en la escuela.

En el tercer eje, -Cómo es mi casa- para las semanas 7, 8 y 9, se trabajaron tres actividades: con la "casita para vivir" se les permitió identificar algunas de las partes de la casa; los "Elementos de aseo" permitió la adquisición de hábitos de aseo en los niños y llevar una vida saludable; se finalizó con "Mis juguetes", donde se reconocieron algunos objetos importantes para el juego y los relaciona con sus nombres.

El cuarto, "Las cosas que me rodean", para la semana 10 , permitió identificar los nombres de algunos elementos del salón que más frecuentemente se utilizan en el desarrollo de las actividades diarias.

Como fase final de valoración de aprendizaje significativo, se inició con un proceso de repaso, en el cual se implementó una aplicación educativa diseñada con el programa de Jclick, con actividades interactivas relacionadas con los talleres desarrollados; luego, se desarrolló la secuencia de asociación de imágenes donde se plasmaron en la pared para que los niños las observaran y después identificaron los nombres correspondientes a las mismas; por último, se aplicó un test de verificación de aprendizajes que tendría la misma estructura del esquema inicial.

\section{Discusiones y resultados}

A continuación, se presenta análisis de tipo descriptivo a partir de la confrontación de los hallazgos encontrados en las sedes Barranco Negro y San Luis Cardonal, involucradas en el proyecto de investigación durante el proceso de aplicación de talleres correspondientes a la propuesta "Las abejitas lectoras".

En primer lugar, se puede reseñar que los resultados fueron positivamente 
similares; de ahí que se corrobora el pensamiento de Ferreiro y Teberosky cuando afirman que no existe una edad ideal para que el niño aprenda a leer y escribir, sino que la adquisición de esta competencia depende única y exclusivamente del estímulo y la motivación que le brinde el adulto que tenga la responsabilidad de cuidado y formación del infante.

La intención de los talleres radicaba, entre otros aspectos, en iniciar un trabajo con aprendizajes contextualizados, aspecto que se apoyan en la teoría de Freire, quien resalta que el acto de leer se configura en la búsqueda por tratar de comprender el contexto social mediante la asociación de la experiencia escolar con la cotidianidad del alumno. En tal sentido, para realizar un trabajo en aula que implicara un acercamiento a la realidad escolar sin desprenderse de su cotidianidad extraescolar, este diseño metodológico de lectura inicial, dirigido a estudiantes de transición, se basó en contenidos teóricos como la etapa logográfica de la lectura que, de acuerdo con Frith, es donde los niños reconocen las palabras como dibujos; la lectura global, descrita por Decroly como la percepción y reconocimiento de las palabras escritas como un todo; y lectura significativa, con Ferreiro y Teberosky, quienes afirman que se debe partir del contexto y además tener sentido y coherencia y no como una simple obligación improductiva. Con lo anteriormente señalado, el desarrollo de estos talleres se procuró alcanzar la meta trazada: que los niños reconozcan imágenes de su entorno y las relacionen con la palabra que la nombran, dando sentido y significado de forma global.

Entonces, el primer eje temático trabajado fue identificarse como personas únicas; de ahí que, se consideró que lo más lógico fuera iniciar con el reconocimiento de su propio ser. Para ello, es vital que cada uno se identificara con el nombre que lo caracteriza. Al respecto, se debe señalar que se cumplió en su gran mayoría con el objetivo propuesto porque los estudiantes, al final del ejercicio, reconocieron su propio nombre y el de sus compañeros; además, hicieron uso de diferentes patrones de referencia como asociación de líneas y símbolos, formas, tamaños y relación con elementos de su entorno. Esta primera etapa continuó con la identificación de las partes del cuerpo, tarea que permitió hacer integración de aprendizajes, relación con el contexto e interactuar de manera divertida mediante el juego y las TIC. Se evidenció el interés de los niños por conocer las palabras que nombran cada una de las partes del cuerpo, integrando conocimientos previos con los nuevos aprendizajes; también se quiso exaltar los talentos de los niños y, a la vez, comprender que las palabras hacen parte de nombres de acciones y eventos, y no solo de objetos y elementos materiales. Aunque, inicialmente, algunos niños se mostraron tímidos, con esta actividad demostraron sus habilidades, aptitudes y la expresión en todas sus dimensiones a través del modelado con plastilina, interpretación de poemas, cantos y la danza, que le permitieron actuar y participar en eventos culturales realizados en la institución. 
El segundo eje temático, -Cómo es mi familia-, inició con un reconocimiento del grupo familiar que fue uno de los más significativos y de fácil asimilación porque los estudiantes pudieron establecer vínculos afectivos, prácticas de valores y normas de convivencia a nivel escolar y familiar; asunto que permitió interiorizar palabras de los nombres de los miembros más importantes de la familia. Asimismo, las prendas de vestir fueron parte del proceso lector de los estudiantes, pues las identificaron y relacionaron con la palabra que las nombran, se permitió establecer diferencias de género, el desarrollo de motricidad fina y gruesa a partir de actividades didácticas. Junto con ello, se familiarizaron con secuencias; mediante el juego, encuentran parecidos de fonética $y$ grafías de palabras aprendidas en talleres anteriores. De igual forma, se cumplió con el deber de la escuela en cuanto a que debe propender por fomento de pautas de conducta y buenos modales para afianzar en el niño la forma adecuada de actuar, hablar y expresarse cuando se comparte en grupo y así favorecer la sana convivencia. Este aspecto permite un mejor trabajo colaborativo, definido por Vigostky cuando manifiesta que el aprendizaje solo se da cuando los niños son capaces de interactuar con otras personas y en colaboración con sus compañeros.

En el tercer eje temático, -Cómo es mi casa-, es un tema de interés para el niño, que facilita la aprehensión de vocabulario relacionado. En este taller, los niños demostraron gran interés por la lectura y escritura al asociar fácilmente la imagen con la palabra, se encontraron algunas dificultades como el temor que sienten para expresarse en forma oral ante sus compañeros y el profesor. Otro tópico desarrollado fue el de los hábitos de aseo con los cuales se permite fomentar desde temprana edad, el aseo y el cuidado de nuestro cuerpo para gozar de una buena salud y aceptación dentro de la sociedad; los niños incorporaron palabras correspondientes a los elementos de aseo como resultado de la interacción con sus compañeros. Asimismo, para esta etapa se retomó el hecho de que el juego es una herramienta poderosa de aprendizaje para los niños; así, pudieron compartir y disfrutar de una sana convivencia y, a la vez, reconocieron el nombre de su juguete preferido, hicieron descripciones de características, como el color, la forma, el tamaño. Además, se hizo reutilización de materiales reciclados para la elaboración de juguetes. Fue un tema atractivo, de fácil comprensión y reconocimiento de palabras con sentido.

Por otro lado, en relación con el eje temático "Las cosas que me rodean", trabajado con el tema mis útiles escolares, se ha de señalar que los niños y niñas desarrollaron la creatividad mediante la descripción de elementos del aula de clase, se percibió en ellos motivación con el picado y el moldeado, donde se trabajó la coordinación visomanual y la motricidad fina que les permitió relacionar las palabras con la imagen y realizaron lectura global y significativa de las mismas. 
Por último, se hace la verificación de resultados. Esta etapa se realizó en tres momentos: se inició con un repaso mediante una aplicación educativa utilizando el programa J click, donde los niños participaron con mucho entusiasmo, resolviendo actividades interactivas en el computador, tales como: reconocimiento de nombres de imágenes, armar rompecabezas, relación imagen/palabra; formar parejas asociando palabra con imagen o imagen con imagen; como resultado, los niños recordaron e identificaron palabras trabajadas en los talleres y las asimilaron con sus respectivas imágenes.

Para el segundo momento se fijaron imágenes en la pared; simultáneamente, encima de la mesa había fichas blancas con las palabras que nombran cada imagen colocadas boca abajo para que, en orden, cada niño eligiera una ficha, la leyera y la ubicara en la imagen correspondiente. Como hallazgo, se encontró que los niños de preescolar hicieron lectura de algunas palabras como un todo en forma global; conocieron el significado y lo contextualizaron; asimismo, se evidenció que los niños presentaron algunos desaciertos, pero que tienden a hacer relaciones y asociaciones de grafemas o fonemas. Otro resultado que se pudo evidenciar en el desarrollo de esta etapa, fue el aprendizaje colaborativo: los niños compartieron saberes, entre ellos, practicaron normas de sana convivencia y se corrigieron entre sí.

De igual forma, gracias al hecho de trabajar en aula multigrado, esta actividad también se desarrolló con los estudiantes del grado primero, con el fin de hacer una comparación respecto de la adquisición de la competencia lectora. Como hallazgo, se encontró que los niños de este grado presentan lectura fraccionada y se demoran más que los estudiantes de transición para asimilar el nombre de la palabra que nombra cada imagen, esto puede hacer difícil la comprensión de su significado.

\section{Conclusiones}

La adquisición de la lectura en la etapa inicial es muy importante para el niño, porque crea vínculos de afecto con el mundo que lo rodea de una forma natural. En su ámbito sociocultural, el niño crece en un ambiente que le es significativo, porque sabe cómo se llaman las cosas, para qué sirven y las relaciona entre sí. Sin embargo, al llegar a la escuela, ese conocimiento se desconoce porque la función de la educación es llevar al niño de conocimientos cotidianos a unos muy generales, y este debe enfrentarse a situaciones que, en su mayoría, son ejercicios mecánicos, extensas planas y actividades impuestas que, de paso, poco o nada tienen que ver con el mundo en el cual se han criado.

Además, la experiencia como docentes con niños de transición llevó a las autoras del proyecto a reflexionar acerca de procesos de lectura que permitieran brindar ambientes de aprendizajes que partieran de la presencia de la cotidianidad dentro del aula. Con tal fin, se desarrollaron algunas estrategias
La adquisición de la lectura en la etapa inicial es muy importante para el niño, porque crea vínculos de afecto con el mundo que lo rodea de una forma natural. 
didácticas, a fin de despertar conciencia del lenguaje a través de ejercicios que les permita relacionar, hacer asociaciones o establecer semejanzas y diferencias. En tal sentido, se trabajaron temas del contexto como la persona misma, su familia, su casa para vivir y las cosas que les rodean. Esto con el fin alimentar esa posibilidad espontánea que trae el niño, de querer leer y escribir, donde sientan placer, alegría y satisfacción por la lectura, que a futuro le permitirá llegar a una lectura formal.

Por lo señalado anteriormente, este proyecto de investigación se puede presentar como una alternativa didáctica complementaria que permite desarrollar potencialmente el proceso de lectura en el nivel inicial. Al tomar como base la lectura significativa, como herramienta de lectura global, se pretende que los niños visualicen las palabras como una imagen; es decir, como un todo y no fraccionada en sílabas y que, por lo tanto, se convierta en hecho significativo. Se recurre a la significación porque mucho se ha discutido acerca de cuál es la mejor manera de aprender a leer; entonces, se han aplicado distintos métodos como el silábico, el fonético y el alfabético, entre otros. Sin querer señalar si algunos de ellos es el más apropiado cualquiera, puede ser el más adecuado se debe recalcar que todos olvidan lo significativo: no establecen vínculos con el contexto. Por ello, se propone que si el niño ya lee la palabra como leer una imagen, le encuentre sentido a la lectura y le es más fácil la apropiación de nuevos aprendizajes.

Entonces, para que la lectura sea significativa se debe partir del contexto, ambiente donde el niño incorpora al texto nuevo lo ya conocido para él. Algo se convierte, en verdad, significativo cuando el niño relaciona lo nuevo con el entorno, cuando une significación al aprendizaje de la lectura. No basta que el niño sepa leer sino que comprenda lo que está leyendo y lo pueda adherir a su conocimiento para que asimile que en las palabras sí hay un significado. Así, el texto puede llegar a ser significativo, al entender que de ellos también se puede aprender y es una manera de llevarlo a la lectura de su contexto escolar, donde no se quede solo en la lectura sino que trascienda, que tenga sentido para los niños y no como una simple obligación improductiva. Así, si la lectura en este nivel de preescolar se torna fundamental, al tomársele sentido, se puede seguir señalando que con la lectura escolar se adquieren las bases que facilitan la adquisición de conocimientos y que los prepara para asimilar aprendizajes con sentido durante proceso de formación escolar y social. 


\section{Referencias}

Bravo, L. (2000). Los procesos cognitivos en la lectura inicial. Santiago de Chile: Pontificia Universidad Católica.

Bravo, L. (Noviembre 2003) La Alfabetización Inicial un Factor Clave del Rendimiento Lector. PU Católica. Fac Educación Santiago de Chile. Recuperado de http://www.psicopedagogia.com/articulos/?articulo=442

Correa, P. (2000). La Lectura en el Nivel Inicial. Buenos Aires. Dirección General de Cultura y Educación.

Díaz, Y., Gamez, M., Rodríguez, G., Vega, S. (2014). Grupos Focales en la Investigación Cualitativa. Recuperado de https://es.slideshare.net/yusethdiaz020/ grupos-focales-en-la-investigacion-cualitativa-ymgsh-4.

Flores, C., \& Martín, M. (2006). El aprendizaje de la lectura y la escritura en Educación Inicial. Sapiens. Revista Universitaria de Investigación, 7 (1), 6979 .

Gamundi, C. (2014). Enseñanza y aprendizaje de la lengua escrita. Cádiz: Universidad de Cádiz.

Giraldo, E. (2010). El Cuento como una Estrategia pedagógica para generar aprendizajes significativos en los procesos de lectura del grado primero. Universidad del Amazonas.

Guzmán, M., Gutiérrez, A., \& Chalela, M. (2009). Proceso de Aprendizaje de la lectura y la escritura. Bogotá: Universidad Santo Tomás.

Herrera, S. (2003). El aprendizaje colaborativo como una herramienta de la actividad Lara, N. (2008). Estrategias para la Enseñanza de la Lecto-Escritura en el grado Primero de educación Primaria. Universidad de Tangamanga. Mexico.

Lozano, L. (2000). Experiencias de Lecto-escritura con niños del grado primero de primaria de la concentración Urbana San Antonio de Ráquira, Boyacá. Universidad de la Sabana Chía Cundinamarca. Tutorial. Campeche: Universidad Autónoma de Campeche.

Martínez, A. (2003). La educación en América Latina: de políticas expansivas a estrategias competitivas. Revista Colombiana de Educación, (44), 12-39.

MEN. (2010a). Aprender y jugar, instrumento diagnóstico de competencias básicas en transición. Bogotá: MINEDUCACION. 
MEN. (2010b). Manual de implementación escuela nueva, generalidades y orientación pedagógica para transicióny primer grado. Tomo I. Bogotá:MINEDUCACION.

MEN. (2016). Derechos Básicos de Aprendizaje. Transición. Bogotá: MINEDUCACION.

Montealegre, A. (1995). Juegos comunicativos, estrategias para desarrollar la lectoescritura. Bogotá: Cooperativa Editorial Magisterio.

Murillo, F. (2010). Investigación Acción. Métodos en investigación en Educación Especial (3- $\quad$ Ed.). Recuperado dehttps://www.uam.es/personal_pdi/stmaria/ jmurillo/InvestigacionEE/Presentaciones/Curso_10/Inv_accion_trabajo. pdf

Nova, A. (2015). La formación integral: una apuesta de la educación superior. Cuestiones De Filosofía, 1(18), 185 - 214. https://doi.org/10.19053/01235095. v1.n18.2016.5363

Pinedo, I., \& Yañez, J. (2017). La dimensión cognitiva de las emociones en la vida moral: los aportes de Martha Nussbauma al estado actual de la discusión. Cuestiones De Filosofía, 3(20), 105-127. https://doi.org/10.19053/01235095. v3.n20.2017.5919

Ríos, R. (2015). Historia de la enseñanza en Colombia: entre saberes y disciplinas escolares. Pedagogía y Saberes, (42), 9-20. DOI: http://dx.doi. org/10.17227/01212494.42pys9.20

UNED. (2003) ¿Qué son las Estrategias Didácticas? San José (Costa Rica): Centro de Capacitación en Educación a Distancia. 